\title{
Peripécias de Humberto Maturana no país da comunicação
}

\section{RESUMO}

O biólogo Humberto Maturana, internacionalmente conhecido pela criação do termo autopoiese, fala também de linguagem e de comunicação. Seu modelo teórico é o do ser vivo como sistema fechado. Daí suas proposições polêmicas, como a de que, na comunicação, nenhuma informação é transmitida, não há diferença entre percepção, ilusão e alucinação e que a linguagem opera sem qualquer referência à realidade exterior. É um novo olhar sobre a comunicação com proposições ao mesmo tempo intrigantes e desafiadoras.

\section{PALAVRAS-CHAVE}

- comunicação

- linguagem

- Humberto Maturana

\section{ABSTRACT}

The biologist Humberto Maturana world-wide known on account of his neologism "autopoiesis" participates on the debates on language and communication as well. His theoretical model relies on the living being as a closed system. From there emerge his polemic statements like these: in communication no information is ever conveyed, there is no difference among perception, illusion and hallucination, the language operates without any reference to the reality outside. His ideas bring a new vision on communication with propositions that are at the same time intriguing and challenging.

\section{KEY WORDS}

- communication

- language

- Humberto Maturana
Autopoiese, descrição e acoplamento

A questão da percepção é tema de um antigo debate filosófico que remete à controvérsia entre aristotélicos e pirrônicos e questiona a própria possibilidade do conhecimento. Enquanto Aristóteles insistia em separar o que é verdadeiro do que é falso naquilo que vemos, estando a terceira hipótese excluída, os pirrônicos (sécs. 4 e $3 \mathrm{aC}$ ) diziam que apesar da dualidade de fato existir, jamais teremos condições, de fato, de saber o valor daquilo que descobrimos, devendo nos contentar em observar a "ordem estabelecida no mundo".

Para os céticos dessa escola é absolutamente impossível saber o que quer que seja, a verdade é algo que se enterra nos mais profundos abismos onde a vista humana jamais penetrará, e os homens não estão de acordo com nada, nem sequer com o fato de que o céu está sobre suas cabeças. As coisas, para eles, não se instalam em nós, elas impõem-se por si mesmas. Isso faz com que elas produzam em cada um impressões diferentes e alojem-se distintamente conforme desejemos concebê-las: o vinho não tem o mesmo gosto na boca de um doente e de um homem são; o ferro, para quem tem os dedos congelados, não é tão duro como para quem não os tem. Além disso, os pirrônicos já sugeriam, no seu tempo, que não nos mexemos, que não falamos, e que o peso e o calor não existem. Tal é o caso também dos cineraicos, dos sécu$\operatorname{los} 5^{\circ}$ e $4^{\circ}$ antes de Cristo, segundo os quais, não percebemos nenhuma sensação exterior, só nos sendo perceptível as sensações internas, como a dor e a volúpia. Som e cor tampouco existem e só há as sensações que elas nos causam.

As posições dos cirenaicos, dos pirrônicos, mas também, posteriormente, dos epicuristas e estóicos conduzem à impossibilidade da ciência: se as aparências comunicadas pelos sentidos são falsas, nenhuma ciência poderá jamais existir. E, se nossos sentidos mudam as condições das coisas que percebemos ou percepcionamos, o que resta desse mundo externo (para von Foerster, constituído somente de intensidades, para Luhmann, um mundo que apesar de existir jamais poderemos conhecer) é inapreensível. Diz Montaigne, no cap. 12 de seu Ensaios, II, que "nós mesmos e os objetos não temos existência constante. Nós, nosso julgamento, e todas as coisas mortais, seguimos uma corrente que nos leva sem cessar de volta ao ponto inicial. De sorte que nada de certo se pode estabelecer entre nós mesmos e o que se situa fora de nós, estando tanto o juiz como o julgado em perpétua transformação e movimento".

Deste debate deveremos guardar pelos menos duas coisas: uma, para este ensaio sobre Maturana, que é a

\section{Ciro Marcondes Filho ECA/USP}


questão da realidade externa (existente mas inapreensível) e outra, para o princípio da razão durante, neste caso, a afirmação subseqüente de Montaigne, de que nada poderemos conhecer do ser porque tudo está sempre nascendo ou morrendo, em condições que só dão de nós uma aparência mal definida e obscura. Tal é o caso, para nós, idêntico, da comunicação: procurar saber o que é ela na realidade é como querer segurar a água, como diz ele, pois tudo está sujeito à transformação e a razão não pode apreendêlo na busca do que realmente subsiste. A razão durante aplica-se a esse processo fluido e não ao estudo de um objeto qualquer nele cristalizado.

O biólogo chileno Humberto Maturana estudou na Inglaterra e nos Estados Unidos a partir de 1954. No final desse período publicou, junto com Lettvin, McCulloch e Pitts, um conhecido artigo chamado "What que Frogs' Eye Tells to the Frog's Brain". Retornando ao Chile em 1960, trabalhou no departamento de biologia da Faculdade de Medicina da Universidade de Santiago. Oito anos depois, junta-se ao grupo de Heinz von Foerster, na Universidade de Illinois, sendo sua principal contribuição à ciência a criação do termo autopoiese, no início dos anos 70, junto com seu ex-aluno Francisco Varela.

Do ponto de vista epistemológico, Maturana ainda estava preso, no período inglês-americano, ao paradigma da uma realidade objetiva exterior independente do observador. Aos poucos, contudo, optou pela exclusão do ambiente e a adoção do modelo de sistema fechado, próprio do construtivismo e da teoria dos sistemas. Mas ainda havia limitações lingüísticas, já que para eles (Maturana e Varela), a linguagem era uma "armadilha que inviabilizava pensar o novo". Daí a criação do termo autopoiese, que remetia a um sistema autônomo fechado, auto-referente e que se constrói a si mesmo.

Para a autopoiese, não é possível explicar fenômenos de um domínio com elementos de outro. Isso remete diretamente a Górgias. Além disso, um sistema autopoiético é necessariamente homeostático, quer dizer, possui um dispositivo para manter uma variável crítica dentro dos limites fisiológicos. Em outras palavras, o sistema sobrevive mesmo que se alterem elementos de sua estrutura organizacional; há uma preservação de sua identidade apesar de sucessivas mudanças em sua aparência (trata-se do "valor próprio" de Heinz von Foerster). Nesse sentido, comenta Beer, Maturana e Varela reformularam a lei de Berkeley - que dizia que o que existe tem que ser percebido, senão não existe - ao afirmarem que o que existe pode ficar irreconhecível quando o vemos posteriormente, que ele pode mudar totalmente a estrutura mantendo entretanto sua organização. Logo, "a coisa" propriamente dita nunca existe de fato.

A inexistência de atributos fixos que definam os seres liquida igualmente com sua teleologia, quer dizer, deixa de existir uma finalidade neles, não há mais um "para quê", os seres simplesmente sobrevi- vem. A ausência da intencionalidade, cara a Husserl e seus seguidores, leva Maturana a dizer também que os sistemas não possuem input nem output como queria a antiga teoria dos sistemas: diante das irritações exteriores eles simplesmente mantêm constantes suas condições de conjunto. Somos nós, os observadores, que lhes atribuímos suas estruturas, suas leis, seu percurso, seu sentido. Maturana e Varela sugerem, para explicar sua lógica, uma analogia com um homem que passou toda sua vida dentro de um submarino e que o único que sabe é manipular seus instrumentos. Quando nós, na praia, vemos o submarino, podemos cumprimentar seu piloto, que desviou-se bem dos recifes e emergiu com muita elegância, mas para ele, que jamais saiu de dentro do submarino, nunca houve recifes nem manobras, ele só fez acionar alavancas e girar botões, estabelecendo relações entre indicadores segundo uma seqüência anteriormente já praticada.

Assim são os sistemas, dizem eles. Vivem segundo suas próprias condições interiores e tudo o que se lhes atribui parte de um observador externo. São fechados operacionalmente e se relacionam com outros sistemas apenas por meio do acoplamento estrutural, conceitos já vistos em Niklas Luhmann. Consciência e mente não fazem parte do cérebro, elas vêm ao "acoplamento social". Se o social não foi bem articulado, ocorrem distúrbios na constituição do sistema nervoso do indivíduo, como no caso do carneirinho que, afastado da mãe algumas horas após o nascimento, não consegue brincar como os outros, perde a chance de se desenvolver plenamente e torna-se separado e solitário; ou o caso das meninas da Índia, que cresceram à margem da civilização e jamais se comportaram como seres humanos.

Se há uma coisa que estabilizou os seres humanos na constituição de sistemas sociais, que mantém constante sua condição de conjunto, isto então seria o amor, diz Maturana. O estabelecimento de domínios consensuais e a geração da linguagem e mesmo da criatividade em geral deve-se, assim, à capacidade de homens olharem outros homens como iguais, de eles cederem sua autonomia e sua individualidade de forma a viabilizar a existência do social.

\section{0 ressurgimento do neopositivismo nominalista}

A primeira sensação que se tem ao ler Maturana é a de que estamos de volta ao solipsismo cartesiano: nossos sentidos nos mentem, tudo depende de um "eu penso" para garantir a existência. Diferente de von Foerster, Maturana não se apressa em desfazer essa impressão recorrendo à alteridade, dizendo que meu eu é destituído de seu trono no momento em que um outro eu igualmente afirma-se. De certa maneira, como já o havia feito Husserl à sua maneira, Maturana recria o cartesianismo. Muito do que ele fala já existia nas Meditações de Descartes: o questionamento da existência do mundo, o procedimento de duvidar de todas as afirmações (Maturana diz: "tudo é dito por 
um observador"), o ato de duvidar da existência dos objetos (a aparente presença das coisas é, de fato, fruto de nossos julgamentos, dizia Descartes na $\mathrm{Se}_{-}$ gunda Meditação), a crença num gênio maligno e esperto que nos quer enganar (a "objetividade sem parênteses" de Maturana, a ser vista), só havendo uma única certeza, a de eu estar aqui pensando, que, para Maturana torna-se na única certeza de os seres realizarem a autopoiese).

Mas a conexão que faz Maturana posteriormente, inclusive adotando conceitos da teoria dos sistemas e do construtivismo, o remete também ao neopositivismo, situando-o como "membro fiel" do Círculo Cibernético, cuja característica está, de fato, em ser uma espécie de continuidade norte-americana no Círculo de Viena dos anos 30. Do positivismo clássico, de Auguste Comte, Maturana havia retomado a precedência da natureza humana (da biologia) sobre a natureza social, a busca de um certo aperfeiçoamento da ordem mundial por meio do altruísmo e do amor. A minimização dos conflitos pela "aceitação do outro", o aparecimento do Homo sapiens pela cooperação e não pela competição, a precedência das relações fraternas marcam um ponto de vista em que o choque, o atrito, as lutas de classes, a vontade de poder, em suma, todos os componentes do modelo agonístico, competitivo, violento e conflituoso como explicação da sociedade não constituem o motor da história nem o destino das sociedades. Os organismos antes se adaptam, se conformam ao interagirem entre si.

Do positivismo e do Círculo de Viena, Maturana extrai seu derivativo, o modo de pensar nominalista, marcado pela separação da linguagem do mundo das condutas sociais consensuais. Segundo ele, a linguagem, diferentemente do sentido que lhe dão os lingüistas, não é constituída de trocas simbólicas, não é a relação de significação e sentido, mas pura e simplesmente uma forma de comunicação (conjunto de comportamentos, gestos, movimentos, sons, posturas corporais), e as palavras são apenas "nós" no que ele chama de "fluir das coordenações de ação". Elas funcionam para atar, para ligar coisas, como no conceito de memória em Luhmann, num fluir em que só interessam as próprias coordenações de ações. Não vem ao caso o quê se fala, mas como as coisas funcionam via linguagem. Linguagem, assim, é formalização e não simbolização, seus usos não interessam e todos os conceitos reduzem-se à situação de signos de um dado ao qual eles permanecem exteriores. Assim, ao debruçar-se sobre a questão "o que levou a que o tamanho do cérebro entre os hominídeos crescesse de 450 para 1450 centímetros cúbicos?" e ao constatar que não foi o uso das ferramentas que provocou semelhante evolução mas a linguagem, Maturana sugere que um comportamento aproximativo, interagente, uma certa socialidade (o toque, o acariciar-se mútuo na convivência de interações consensuais) foi o que provocou o surgimento do homem, não o discurso propriamente dito. Bastou a convivência e as intera- ções, em uma palavra "seu modo de vida", para que ocorresse o crescimento do cérebro.

Desta maneira, como no estruturalismo, especialmente o lacaniano, que não esconde sua simpatia pelo pensamento cibernético, como conhecemos em Friedrich Kittler, a exclusão da significação lingüísti$\mathrm{ca}$, o fato de tomar a linguagem apenas como um sistema operacional, como algo formal tal qual a matemática e não mais culturalmente simbólico, nos conduzem fatalmente a uma redução do lingüisticamente possível ao tecnocraticamente validado, nos levando ao beco sem saída do nominalismo. Maturana, ao ser perguntado sobre o substrato que sustenta tudo isso, diz que a coisa é insondável, porque tudo o que temos só pode ser colocado em termos de linguagem. Logo, o que está fora desse círculo deve ser ignorado. As experiências que não estão na linguagem, diz ele, ao estilo do bispo Berkeley, "não existem". Que não há modo de fazer referência a elas nem mesmo ao fato de tê-las tido. Que o próprio "não posso descrever" já pertence à linguagem. Indo além de Wittgenstein em seu famoso "sobre aquilo que eu não posso dizer devo calarme" - que significa que para Wittgenstein os únicos meios para tratar dos problemas filosóficos jamais seriam a linguagem, que não há apenas os problemas da linguagem, reconhecendo, ao contrário, a existência do místico e o que não poderia ser escrito e que era, de fato, o mais importante -, Maturana diz que se eu não puder nomear as coisas, então elas não existem, se o homem não pode falar, então ele não pode falar.

Mas o público que assiste à sua exposição não se conforma com isso e de um participante surge a inevitável alusão ao inexprimível: Édipo foi um sujeito que sofreu tudo, até teve os olhos arrancados. Entretanto, no final, Édipo morreu em Colona, e o poeta diz sobre a morte de Édipo que ele "tinha uma expressão tal de paz e doçura, que nenhum mortal poderia descrever". Maturana ouve e responde: por mais que eu diga com palavras deste mundo, a única coisa que se pode dizer sobre a paz e a doçura que o rosto de Édipo tinha é que não se pode dizê-lo. A realidade, para o biólogo, não existe, não há modo de trazê-la à mão, logo, não se pode falar dela.

Ora, se tudo o que temos só pode ser colocado nos restritos termos da linguagem, e se a esta não importam os conteúdos, como se justifica que a linguagem esteja na base de tudo o que constituiu o humano? Só pode ser se a linguagem for tomada como mero espírito que interliga todo o processo social, uma espécie de alma, de élan vital a dar energia e vida aos relacionamentos humanos. Mas há um problema: sendo conjunto de movimentos, gestos, posturas, sons, ela tem que incorporar tudo, inclusive o não-dito (o não-exprimível, o não-sígnico e o não-simbólico, o lingüisticamente incomunicável, as sensações e os sentimentos), ou seja, também o fora da língua. E aí sobressai a ambigüidade com que ele opera o termo "linguagem", ao mesmo tempo usada de formas opostas, ora com um uso amplamente abrangente, ora como um concei- 
to de uso severamente restritivo; ora como comunicação genericamente, envolvendo tudo o que é humano, inclusive o não-lingüístico, ora como algo só formal, "aquilo que as palavras conseguem expressar", no sentido da filosofia analítica de Russell, do Círculo de Viena e do campo simbólico de Lacan.

Essa contradição vai repercutir no projeto intelectual de Maturana como um todo pois, ao fechar com o nominalismo de uma redução do mundo ao que podem as palavras dizer, no estilo dos engenheiros e programadores de computação, que crêem que tudo pode ser sintetizado pela linguagem computacional e nada escapa ou vai escapar disso, ele inviabiliza a crítica ao pensamento tecnocrático que, em verdade, é o que ele defende explicitamente como filosofia existencial: supressão do uso de computadores por crianças até certa idade, subordinação da técnica ao "espaço do viver", opção pela relação professor-aluno em vez do uso de sistemas audiovisuais, como ele expressa claramente em Ontologia da Realidade (p. 336).

\section{Os sistemas vivos e o método científico}

Sistemas vivos são máquinas autopoiéticas. São máquinas que produzem a si mesmas e que não possuem intenção ou meta, apenas vivem. São sistemas fechados e sua relação com o meio externo é de tal forma que ambos são fonte de mútua irritação, ambos desencadeiam, um no outro, mudanças de estado por meio do acoplamento estrutural. Tudo isso já conhecemos de Niklas Luhmann. Por ser essa a única definição do ser vivo (a de ser autopoiético), deixam de ser fatos constitutivos nossos ocorrências como crescermos, nos reproduzirmos e morrermos. Em vez disso, basta à máquina autopoética unidade e organização. A organização é aquilo que define a identidade de cada uma. Ela é o que se mantém invariante (o valor próprio de von Foerster) o tempo todo, mesmo quando suas estruturas alterem-se continuamente.

Uma explicação científica para Humberto Maturana compõe-se de quatro passos ou condições:

1 Que fenômeno eu pretendo pesquisar? Que deve ser lido, em verdade, da seguinte forma: que condições o observador deve satisfazer para ter a experiência que se quer explicar;

2 Que processo gerativo ou mecanismo ad hoc deve ser proposto, de tal forma que gere o fenômeno a ser explicado;

3 Como deduzir, a partir de coerências operacionais vindas da operação do mecanismo gerativo descrito em no item 2, outras experiências não consideradas em sua proposição;

4 Como demonstrar a operacionalidade e a experimentação do que foi deduzido no item 3 por um observador que satisfaça as condições requeridas.

Como se vê, desaparece o objeto propriamente dito. No item 1 fala-se, em verdade, das condições a serem satisfeitas na experiência e o enfoque central está no item 2, o principal para Maturana, a identificação do processo gerador do fenômeno. Privilegia-se em primeiro lugar o mecanismo, aspecto central de uma explicação científica, aquilo que produz o fenômeno, para se ver depois a coisa produzida. No caso da linguagem, visto acima, convém antes conhecer seu mecanismo gerativo, os contatos humanos, para depois estudar seu objeto ou seu resultado, o discurso. Maturana diz que para entender o ser vivo, o que temos que encarar é o que ele faz, o que ele fabrica e diz: "Qual a tarefa ou o propósito da mosca? É mosquear, ser mosca".

Mas isso só pode ser uma brincadeira, pois a finalidade não faz parte da autopoiese do ser, disse ele acima. Logo, a pergunta pela finalidade, segundo o método do próprio Maturana, só pode pertencer ao nosso discurso sobre a ação da mosca, estando no campo das descrições, do observador, não da mosca. Pesquisando o mosquear é que descobriremos o ser da mosca.

Já que desaparece o objeto, entra em crise igualmente a noção de objetividade. A proposição metodológica de Humberto Maturana implica um debate subseqüente a respeito das explicações científicas clássicas em confronto com sua própria formulação de ciência. Para as primeiras, Maturana cria o rótulo objetividade sem parênteses (OSP); já, no caso de sua ciência, uma ciência que não se ocupa com objetos, que "não precisa do mundo dos objetos para operar", mas ocupa-se com processos produtivos, o título que dá é objetividade entre parênteses (OEP). A OSP considera a existência de entes que estão lá independentemente das pessoas: matéria, energia, consciência, Deus, e o pesquisador coloca-se na situação de acesso privilegiado à realidade. Na OEP, ao contrário, não se pode fazer nenhuma referência a entidades independentes de mim para construir minha explicação.

Com o desenvolvimento de sua teoria, Maturana não falou mais que "a realidade não existe", mas sim que há tantas realidades quanto observadores. $\mathrm{Na}$ OEP, assim, há tantas realidades quanto domínios explicativos, sendo todas legítimas. Por outro lado, um pesquisador dentro do modelo da OSP jamais será responsável pela validade do que diz, porque aquilo não é produto de sua realidade mas "do mundo". Já, um pesquisador que adote o modelo da OEP afirma diferentemente. Aqui, diz Maturana, eu sei que o outro pesquisador está num domínio de realidade diferente do meu, igualmente válido, apesar de não me agradar.

Maturana advoga o método da OEP porque acredita que aqui ele pode encontrar um espaço de convivência baseado na compreensão da natureza biológica, pois, já que seres humanos não distinguem percepção de ilusão, tudo dependendo do observador, pode haver, segundo ele, respeito de um pelo outro. É possível, acredita ele, que possamos criar um espaço no qual as diferenças não entrem em consideração, quando, por exemplo, um pesquisador diz a 
outro: “Ah, então você pensa em fazer isso, que interessante! Eu prefiro fazer outra coisa". Pesquisadores que trabalham no campo da OEP não se submetem a outros, acredita ele. O que pode haver é apenas "sedução", quer dizer, um aceita o outro e incorpora em seu domínio como parte sua e passa a esse domínio sem negar-se a si mesmo: "Ah, veja você, que bonito, eu não havia visto todas as conseqüências disto".

As críticas à pretensa objetividade científica são conhecidas. Em torno dela constroem-se poderes acadêmicos e intelectuais que determinam o que é certo e o que é errado baseado apenas na posição de liderança de alguns. E, efetivamente, explicações particularizadas a respeito de uma realidade "que está aí" acabam imperando quando partem desses grupos monopolizadores do saber. Não é novidade o processo de uso e exploração do poder (político, econômico, de prestígio) das comunidades científicas e a exclusão de quem não faz esse jogo. Mas nada prova que também o método OEP de Maturana não se transforme mais cedo ou mais tarde numa OSP.É o que questiona um membro do público que assiste à sua conferência: "as explicações entre parênteses vão da realidade através dos parênteses... Não vejo como o senhor quer negar um fato fundamental por necessidade didática, mas ao final vamos chegar a um encadeamento com aproximações sucessivas dos parênteses em direção a um sem parênteses, que evidentemente não podemos conhecer". Quer dizer, no metadiscurso, a própria proposição de Maturana cai no plano da OSP, e isso se vê inclusive na própria formulação retórica, quando ele diz "Isso não é correto" (2001, p. 110), num tom muito apropriado à OSP. Só seria diferente - e coerente com seu discurso - se ele dissesse que a OSP também é correta (o que é inviável).

Maturana responde a isso aludindo ao respeito de um pelo outro. Mas a resposta é sofista. Ele diz: eu nego o outro porque não me agrada o domínio da realidade em que está e não porque esteja equivocado. Ora, ele está dizendo que o outro é igualmente válido, mas não lhe agrada e o que não lhe agrada? Exatamente o domínio da realidade em que está. E por quê? Porque não acha correto, cai-se, portanto, no mesmo esquema da OSP. O biólogo acredita poder acomodar todas as visões de mundo dentro de seu projeto OEP. Lá há tantas realidades como domínios explicativos e todas são legítimas. Mas essa lógica continua a negar a existência de um mundo independente dos observadores. O debate sobre isso será o tema do próximo capítulo. Por ora cabe apenas dizer que a afirmação de que percepção é o mesmo que ilusão é, no mínimo, grosseira. Há graus de deformação da realidade. Melhor seria dizer que há realidades e há domínios explicativos, mas os níveis não mantêm correlação entre si.

A existência de uma realidade não pode ser demonstrada, naturalmente, apenas pelo consenso co- letivo: isso é uma pirâmide, isso é um oceano, etc., porque não raro há mutilação na percepção até mesmo de toda uma coletividade (como no caso dos fanatismos da Inquisição, dos nazistas que se tornaram neuroticamente cegos diante dos judeus e outros casos). A existência de algo independente dos observadores pode ser constatada nos registros fotográficos, cinematográficos, fonográficos, cuja imperfeição pode não capturar tudo ou tudo de forma absolutamente fiel - a não ser que tenha sofrido um desvio técnico intencional por parte do operador - mas não se pode dizer que sejam ilusão ou fabricação pessoal do sistema perceptivo do observador.

Veja-se, por exemplo, o caso da frase "Claro, você não vê os defeitos do outro porque gosta dele" (2001, p. 44), que Maturana utiliza para dizer que, segundo a OSP, a pessoa é cega diante da realidade em si (logo, sofre a pressão do outro para dobrar-se a ele). Parte da frase está certa, mas porque há diferentes níveis de ilusão, umas mais radicais, outras menos evidentes. E isso tudo tem a ver com uma categoria que é fundamental em toda esta discussão, que é o interesse, que é um tema que Maturana não toca, reduzindo toda essa dimensão a simplesmente "emoções". Ele não se incomoda com os móveis da ação. A cegueira é maior ou menor conforme o interesse envolvido. Não se trata de "acesso privilegiado à realidade em si", mas de acessos diferenciados conforme o envolvimento emocional, conforme a cegueira de cada um.

Também na questão da sedução, quando um pesquisador reconhece "que bonito, eu não tinha visto todas as conseqüências disso", trata-se de uma situação muito específica de convergência de pessoas onde não há o conflito nem a competição. Maturana diz que se aceita estar com o outro "simplesmente porque sim, sem negar a si mesmo" (2001, p. 123). Ocorre também em situações de ignorância ou desconhecimento (ausência de informações anteriores) quando esta informação ainda não pôde ser atrelada a valores. Quando se conhece, quando se toma posição, uma frase dessas já não se coloca, pois vincula-se a valores de cada um e a interesses. E, pelo que sabemos, a situação onde imperam os interesses representa a quase totalidade de toda a competição científica.

Em síntese, Maturana nega os "especialistas", os estudiosos, aqueles que se aprofundaram num certo objeto, pois tudo que eles estudaram teria sido mutilado pela sua ilusão perceptiva. O conhecimento, portanto, é impossível, da mesma forma como vimos na introdução. Ora, a solução que apresenta tampouco satisfaz, pois, se uma tende, no limite, à postura autoritária, a outra tende ao vale tudo: "qualquer afirmação minha é válida no contexto das coerências que a constituem como válida." Privilegiando-se o "mecanismo cognitivo" em vez do objeto tende-se à atomização do saber, "vale o que cada um pensa", ao estilo do pós-moderno, e o fato de terem existido, por exemplo, os campos de concentração, deixa de ser um 
acontecimento para ser uma questão de opinião (cf. 2001, p. 37).

\section{A realidade externa e o caso da salamandra}

O sistema vivo não se orienta a uma meta, é um sistema fechado, estável, determinado pelo seu próprio estado e modulado por interações não especificadas por sua conduta. Estas modulações, contudo, só são evidentes para o observador que vê o organismo a partir de fora. Para o funcionamento do próprio sistema, tudo o que existe são seus próprios estados. Por esse motivo, não podemos caracterizar o substrato responsável para que as interações possam ocorrer como sendo propriedades independentes do observador. Daí dizer Maturana que a realidade, como universo de entidades independentes, é necessariamente uma ficção, pois pertence ao domínio puramente descritivo do observador. Por esse motivo, acha ele que não tem sentido falar de mundo real, objetivo, independente do observador. Nem mesmo na forma que encontram seus colegas construtivistas, dizendo que ele está aí, mas eu não posso conhecê-lo.

Os sistemas vivos são fechados e abertos ao mesmo tempo. Enquanto sistemas moleculares, diz Maturana, eles estão abertos ao fluxo de energia e matéria. Mas como sistemas autopoéticos, eles estão fechados dentro de sua dinâmica de estados, isso é, enquanto suas mudanças estruturais conservarem sua autopoiese. Mudanças estruturais, portanto, só podem surgir pela operação das propriedades de seus próprios componentes. O meio jamais determina essas mudanças. No máximo, ele desencadeia mudanças que vão se operar internamente pelo próprio sistema. Um exemplo disso é o sistema nervoso enquanto rede neural fechada e cuja estrutura está em contínua modificação por meio da interação de seus componentes. Um observador o vê tanto como essa rede fechada promovendo alterações internas, quanto como um sistema que tem contato com o ambiente externo por meio de suas superfícies sensoriais. Essas superfícies sensoriais percebem perturbações do ambiente externo. Assim, perceber para Maturana não é a captação de traços do mundo exterior; ao contrário, é o fato de um organismo constituir um mundo de ações mediante correlações senso-motoras congruentes com as perturbações do meio. Quer dizer, ele constrói seu mundo de forma correlata a partir do que ele vê. Por isso, a realidade não existe.

O mundo real não existindo, tampouco existem os objetos. Eles surgem na linguagem, diz Maturana. Mas não no sentido que vimos atrás, Caps. $1 \mathrm{~g}$ e 1i, dos antigos faraós da religião egípcia, que constituíam as coisas do mundo na medida em que falavam, mas diferente. Antes da linguagem não há objetos e não os há porque sua existência, diz ele, é trazida à mão pelo observador. "Se no momento em que estou na linguagem surgem os objetos, posso fazer história, como uma construção numa dimensão particular, que cha- mo de passado, das coerências operacionais de meu operar na experiência no momento presente da linguagem. E aí surgem as árvores, as plantas, as moléculas, o Big Bang na história física do universo físico" (2001, p. 100). Tampouco a reflexão subjetiva, interior, pode ocorrer fora da linguagem, pois só ela pode permitir, acredita ele, a distinção entre interior e exterior. Não obstante, Maturana afirma que ao operar na linguagem as fisiologias mudam e muda o próprio fluir na linguagem, surgindo daí a poesia, a partir dessa "base invisível" que é diferente do que ocorre na linguagem.

Recordemos, de passagem, a citação de Maurice Merleau-Ponty sobre dois observadores, eu e Paulo, que olhamos uma mesma paisagem, tendo ambos sensações próprias, incomunicáveis e sendo a paisagem distinta para cada um de nós. Diz Merleau-Ponty que quando eu aponto para um determinado lugar, meus gestos invadem o mundo de Paulo e vemos, juntos, a paisagem do mundo: o mundo não é mais objeto, mas campo de nossa experiência. Para Maturana, os objetos que dois observadores em conversação descrevem surgem não como "paisagem do mundo", já que este não existe mas, como tais, somente na linguagem, "como forma de coordenação coontogênica de conduta". A diferença entre ambos é que, em Merleau-Ponty, as subjetividades dissolvemse na "carne do mundo", não há mais eu nem você, há um mundo que nos incorpora; já Maturana (e Varela) dizem que, de fato, habitamos um mundo, mas não podemos separar a história de nossas ações - biológicas e sociais - de como ele nos parece ser.

A demonstração mais famosa dessa tese de Maturana está na experiência com a salamandra, animal que atira a língua para fora e captura vermes, traças e moscas, que ele traz para dentro em sua língua pegajosa. A experiência é a seguinte: os cientistas cortam a borda de um olho do girino, sem atingir seu nervo óptico, e giram o olho 180 graus. O resultado é que ele passará a ver diferentemente com cada um dos olhos. Com o olho normal, ele continua a acertar as moscas e os vermes de que precisa para se alimentar; com o olho adulterado ele projeta a língua com um desvio de 180 graus. Ele projeta a língua, diz Maturana, como se a zona da retina onde se forma a imagem da presa estivesse normal. Com isso, ele constata que para o animal não existe acima ou abaixo, de frente ou de trás, apenas correlação entre externo e interno. Essa seria obra do sistema nervoso, executar a correlação sensóreo-motora entre retina e movimento da língua e não o mapa do mundo externo. Alterando-se a estrutura do organismo altera-se a percepção, diz ele, e se a captação depende do instrumento, do olho, o que ele mostra já não é mais característica do objeto.

É dessa demonstração que Maturana extrai a afirmação de que não há diferença entre percepção, ilusão e alucinação. A captação de imagens e de sons, diz ele, não se dá como se fosse uma linha telefônica, 
um mero meio de ligação entre mundo externo e cérebro. O externo é um burburinho, como na bolsa de valores, e daí, diz ele, cada um ouve ou vê o que lhe interessa. Daí ele dizer também que o cérebro não capta nada do meio, que ele fabrica mundos. Nesse aspecto ele é diferente de von Foerster, que diz que há uma captação de intensidades que são reinterpretadas conforme as estruturas do sistema. A salamandra, quando lança a língua para capturar o bichinho, não está apontando para um objeto externo, diz ele, ela faz apenas uma correlação interna, com o sistema motor. Somente um observador acredita que ela mire um objeto, da mesma fora, complementa ele, que só para o observador que o relógio dá a hora.

O fato do sistema nervoso não capturar o mundo, nem mesmo as puras intensidades, mas fazer suas correlações internas não convence inteiramente. Uma mesma casa que na nossa infância parecia muito grande, espaçosa e interminável, na vida adulta assume as suas formas reais e discretas. O sistema gerou suas correlações concretas adequadas às circunstâncias do organismo, mas a casa jamais foi uma ficção, uma obra de minha imaginação, ela tem dimensões concretas, constatáveis por qualquer um, independente das variações subjetivas de seus observadores. Certamente não há "cópias" porque a mente retraduz o que vê lá fora a seu modo, daí nossas recordações parecerem "tão diferentes" quando voltamos aos mesmos lugares; igualmente - e ainda mais fortemente - $\mathrm{o}$ inconsciente registra traumas "à sua maneira", quer dizer, de forma irreconhecível. Mas há um tipo de imagem mental que não pode ser negada e que é fabricada pela própria mente a partir do mundo externo.

A experiência com a salamandra demonstrou apenas que um olho mutilado em laboratório produziu no animal um erro na sua captação do objeto visado pelo seu olho, não que a mosca não existisse. Houve a provocação de uma deturpação, porque agora a salamandra lança a língua, mas não atinge o objeto. Criouse um desajuste entre posição real do objeto e lançamento da língua. O desarranjo foi interior, criando problemas de identificação e captura, e a provocação de uma anomalia significa que o sistema agora erra por danificação de seus instrumentos. Maturana diz que os animais não cometem erros, mesmo que morram de fome por nunca mais conseguirem pegar a mosca. Isso não sabemos, pois, com dois olhos mutilados, eles irão fatalmente morrer por não encontrar forma de sobrevivência. Para Maturana, os cientistas convencionais estão acostumados a ver uma "salamandra esperada" que, não operando o acoplamento estrutural, erram por não perceber o mundo exterior adequadamente, desintegrando-se. Em oposição a esta, diz ele, há uma "salamandra não esperada" que, a partir da intervenção cirúrgica no olho, continua operando seu acoplamento estrutural sem cometer erros, enquanto conserva sua organização e sua adaptação.
Assim, errar na mosca é erro somente para nós, não para a nova salamandra operada, cujo organismo "adaptou-se" à nova situação. Em verdade, diz ele, ela acerta ao errar no alvo.

\section{Comunicação e linguagem}

Humberto Maturana explica a linguagem como sendo um processo genuinamente conotativo, isto é, um processo em que não há transmissão de informações. Isso parece singular dentro dos estudos de linguagem e comunicação. Da mesma forma, não há transferência de pensamento do falante para o interlocutor. $\mathrm{O}$ que ocorre é o fato de o ouvinte criar informações reduzindo sua incerteza por meio de suas interações em seu próprio domínio cognitivo. Para ele, linguagem é, antes, um sistema de comportamento orientador, ela está lá para criar um domínio consensual de comportamento entre sistemas lingüisticamente interagentes por meio do desenvolvimento de um domínio cooperativo de interações. Imaginemos dois organismos. Havendo coerência na prática de suas interações, eles irão adaptar-se mutuamente e assim permanecer pelo tempo que durar essa coerência. Cada interação, diz Maturana, leva a uma seleção de uma mudança estrutural particular. Ocorrendo isso, estabelece-se um domínio lingüístico.

Maturana busca entender a linguagem a partir inicialmente da função biológica que atua nas interações. A função biológica permite destacar em primeiro lugar sua função conotativa - as expressões sem palavras, as funções de entrosamento e de congregação da proximidade entre os homens, sua relação com o comportamento comum - e não suas formas simbólicas denotativas; ela permite realçar a função de orientação do orientado dentro do domínio cognitivo e não apontar para entidades independentes (os signos). Desta maneira, as interações aprendidas de forma orientada incorporam primeiramente uma função de origem não-lingüística; esta função, levada a um uso recursivo, pode conduzir evolutivamente ao tal sistema de interações consensuais entre organismos, que são as linguagens naturais.

O curioso nesta interpretação do processo lingüístico é que, para Maturana, a linguagem e o operar do observador não requerem nem dão origem a referências da realidade externa (1997, p. 73). Palavras existem, mas não exatamente para significar coisas; elas funcionam como nós de coordenações de coordenações de conduta. Palavras são os gestos, os sons, as condutas, as posturas corporais que atuam no fluir recursivo das coordenações consensuais de conduta que constituem a linguagem. O que existe, portanto, é apenas esse processo, esse mecanismo, o fluir recursivo das coordenações consensuais de conduta.

Desta maneira, sendo as interações comunicacionais e lingüísticas intrinsecamente não-informativas, um organismo A não determina jamais a conduta de um organismo B, ambos são organizações autopoiéti- 
cas, e cada mudança sofrida por cada um deve-se única e exclusivamente à sua própria organização. $\mathrm{O}$ domínio lingüístico não tem nada a ver com o domínio autopoiético. Um pode gerar elementos do outro, mas eles não se interseccionam.

Mas um organismo pode mudar o comportamento de outro. Isso ocorre pela interação ou pela comunicação, que são diferentes formas de relacionamento. Numa interação, ambos organismos dirigem-se, um ao outro, e o comportamento resultante de um depende do comportamento do outro. Maturana cita, para este caso, o exemplo da corte e da luta. Na comunicação, distintamente, o comportamento de um organismo é orientado para o domínio de interações de outro organismo; esta orientação é diferente de sua interação atual, mas comparável à orientação do organismo orientante. Os comportamentos não ficam interconectados, pois são autopoiéticos, mas demonstram condutas paralelas. Este segundo caso, o comportamento comunicativo, é base para qualquer comportamento lingüístico, diz Maturana. Comunicação, portanto, éo seguinte: "O primeiro organismo gera (de forma evidente para o observador) uma Descrição de seu nicho que, somado à sua própria significação enquanto um comportamento (dentro do domínio cognitivo do primeiro organismo e independentemente dele), orienta o segundo organismo, dentro de seu domínio cognitivo, para uma interação da qual surge uma conduta paralela à do primeiro mas não relacionada a ele" (1972, p. 29).

O organismo que orienta terá, de nossa perspectiva como observadores, a função denotativa, pois ele aponta para um aspecto do ambiente que o segundo organismo localiza em seu nicho, ele o descreve e o trata como algo externo. Já, da perspectiva do segundo organismo, o que é orientado, ele tem a função conotativa. Ele implica uma interação dentro de seu domínio cognitivo. Esse domínio, no caso de se atualizar, irá originar um comportamento que descreve um aspecto particular de seu nicho. É do lado do orientado que a conotação atua, não do orientador.

Comunicação, assim, são essas condutas coordenadas, que são mutuamente desencadeadas entre membros de uma comunidade. Nenhuma informação é transmitida na comunicação. Cada um diz o que diz e ouve o que ouve segundo sua própria determinação estrutural, diz Maturana. É a realização, em dois indivíduos, de suas respectivas autopoieses. Para o observador externo, complementa, interessa o significado, mas para ambos os atores interessa apenas o acoplamento estrutural de si mesmos. No processo de comunicação reflete-se um homomorfismo de comportamento resultante desse acoplamento estrutural. Mas isso não basta. O homomorfismo de comportamento é trivial (no mesmo sentido que usa von Foerster). A situação comportará novidades quando, por meio de acoplamento estrutural ontogênico, do primeiro contato e da configuração de um domínio consensual comum, a coisa mudar. Diz Maturana: “Não há dúvi- da que gostaríamos que o outro ouvisse o que dizemos, mas isso não acontece, a menos que venhamos interagindo recursivamente um com o outro por um período suficientemente longo para nos tornarmos estruturalmente congruentes, resultando em sermos capazes de comportamento coerente no conversar um com o outro. Quando isso acontece, dizemos que compreendemos um ao outro" (2001, p. 174). Assim chegaremos ao não-trivial: já não há mais um homomorfismo de comportamento e cria-se um novo sistema que eles constituem juntos. Neste sentido, a comunicação chega, por caminhos absolutamente diversos e inesperados, à nossa proposta da Nova Teoria da Comunicação, inscrita nos termos da razão durante: a comunicação como criação do novo a partir do entrosamento entre dois seres em diálogo.

Humberto Maturana diz que quando a comunicação puder aparecer como "semântica", ela já pode ser relacionada ao domínio lingüístico. Aqui ele distingue dois tipos de condutas comunicativas: as lingüísticas e as instintivas, convergindo para a diferenciação que fizemos entre comunicação e linguagem em outro lugar: comunicação como o campo maior do comportamento humano, de onde a linguagem emerge como território específico. Uma cultura constituise, em Maturana, como uma rede de "conversações", que define o modo de viver, de orientação, assim como um modo de atuar, de emocionar e de crescer nesses dois âmbitos (atuar e emocionar). Essas conversações são como que um background espontâneo e natural.

Linguagem e, em sentido mais amplo, comunicação são acima de tudo comportamentos orientadores. Pela linguagem cria-se esse "domínio consensual de comportamentos" que ocorre pela ação cooperativa das interações. Ela surge das relações de intimidade que se estabelecem no primata bípede. Mas são relações conotativas, calcadas em comportamentos de aproximação e de troca mais instintiva que verbal, onde os organismos autopoiéticos mantêm-se fechados no que são. $O$ fato de a linguagem e o operar do observador não fazerem qualquer referência à realidade externa sugere que estamos diante de um grupo de autistas, isolados em seu próprio mundo. As pessoas se encontram, se relacionam, agem em comum através dos gestos, dos sons, das posturas do corpo e assim constituem formas consensuais, um ambiente que ele próprio é a linguagem.

Evidentemente, a comunicação é também o acoplamento estrutural dos participantes através de processos meramente conotativos, mas é difícil excluir daí a importância e o valor dos símbolos especificamente lingüísticos, como se isso fosse mero detalhe de um processo maior. Palavras não são só nós, como pretende essa forma nominalista de representar a comunicação. Vimos, no capítulo precedente, que uma certa "base invisível" faz surgir a poesia das palavras. $\mathrm{O}$ que constitui essa base, Maturana nunca nos disse. Os símbolos fazem parte decisiva nessa coordenação de coordenações de ação. Não são apenas "referência 
ao que se passa na linguagem" (1997, p. 343). De fato, cada um diz o que diz e ouve o que ouve segundo sua própria determinação estrutural mas o que ele diz ou o que ele ouve não são meras fabricações autistas de seu organismo autopoiético, são elementos de uma linguagem compartilhada. Eu ouço o que eu quero ouvir, mas dentro de um universo de palavras realmente existente, de onde extraio o significado que me interessa. A metáfora da bolsa de valores supõe que vozes e palavras são usadas e não apenas urros e comportamentos animais. A cada um interessa, de fato, o acoplamento estrutural, mas não é só ao observador que interessa o significado pois, de cada signo denotado, cada organismo realiza internamente sua própria significação no processo autopoiético. Logo, os signos são também importantes por carregarem em si essa tal "base invisível", que Maturana prefere não tocar.

Maturana diz que dois organismos podem entrar em interação ou em comunicação. Sendo que a primeira, onde os comportamentos se determinam reciprocamente, é característica da corte e da luta, logo, do conflito. Comunicação, propriamente dita, só surge na convergência. Um organismo "orienta" outro organismo para uma interação, surgindo daí uma "conduta paralela" se bem que não igual à do primeiro. É curioso que Maturana restrinja as formas de comunicação à comunicação cooperativa e jamais veja na violência e na agressividade que, afinal de contas, também marcaram o desenvolvimento das civilizações, formas notórias de comunicação.

\section{"Nós criamos o mundo" mas inconscientemente!}

Humberto Maturana acredita que a natureza é, para o ser humano primitivo, o reino de Deus. Nela ele encontra à mão tudo do que necessita, bastando para isso viver harmoniosamente com ela. Para o ser humano moderno, o reino de Deus, a natureza, é a sociedade e o fator estabilizador básico na constituição de um sistema social é o amor, o ato de ver o outro como parceiro em algumas ou em todas as dimensões da vida. Para que a linguagem surgisse entre os humanos, uma emoção - no caso, o amor - tornou possível que as pessoas recorressem a interações de convivência, complementa ele. E o amor é um fenômeno biológico que não requer justificação, um encaixe dinâmico recíproco espontâneo dos seres. Certamente há ódios, lutas e matanças, mas tudo acaba na aceitação do outro e nos movemos nessa oscilação entre negação e aceitação; após as destruições, os fracassos e as guerras sempre irá aflorar o amor.

Segundo sua visão de mundo, a origem antropológica do Homo sapiens ocorreu pela cooperação e não pela competição. Maturana só aceita como sistema social aqueles sistemas que são constitutivamente sistemas amorosos, onde reinem as relações fraternas. Onde há competição, não temos mais sistemas sociais pois, para ele, "competição não é uma relação social" (2001, p. 109). A linguagem originou-se de certa inti- midade no viver cotidiano, na partilha dos alimentos feita por nossos antepassados, na sensualidade, na participação dos machos na criação dos novos seres, tudo isso marcado pela emoção do amor.

Há, naturalmente, em toda essa interpretação do processo antropológico de constituição do Homo sapiens, um componente fortemente idealista, de inspiração cristã. Isso, possivelmente, serviu de base à sua adesão ao positivismo, apontado no início, responsável por sua vinculação do social ao biológico. Expusemos, acima, a dívida de seu método para com Auguste Comte (o biológico precedendo o social, precedência do altruísmo e do amor) e com o positivismo de uma forma geral, como modelo explicativo que minimiza a importância do conflito e da contradição na sociedade. A cooperação, o entrosamento, as relações de solidariedade são colocados como matrizes das interações sociais, num mundo onde reina o amor e os homens têm boa vontade uns com os outros.

À parte esta ingenuidade na apresentação de processos sociais, históricos e civilizatórios, a proposição de Maturana perde a inocência quando solicitada pela história presente para se manifestar. O caso, por exemplo, dos estudantes universitários que protestavam em Santiago diante do fato de um colega ter sido preso, é ilustrativo. Maturana diz que o protesto deles era falso, porque partia da emoção. O discurso era legítimo mas, diz ele, não se associava às ações que têm a ver com a aceitação do outro nas circunstâncias em que ele se encontra. E conclui: se é certo que queremos uma convivência na aceitação do outro, temos que levar em conta quais são as condições biológicas, em última instância, que tornam possível essa convivência. Assim, o protesto, em sua opinião, deveria partir para o exame das formas de convivência entre protestantes e a polícia, sujeito a desaparecer nos meandros da burocratização, do legalismo e do positivismo jurídico.

Mas, o que mais suscita controvérsias em seu método é, inegavelmente, a afirmação do desaparecimento da realidade pelo argumento de que percepção, ilusão e alucinação são a mesma coisa. Diz Maturana que nós literalmente criamos o mundo no qual vivemos, vivendo-o. Estamos quase próximos, portanto, de Marx quando este diz que o homem faz sua própria história. Só que Marx não pára aí, já que isso seria idealismo "burguês", a segunda parte da frase é que é mais importante. Nós não a fazemos como queremos, mas sob condições historicamente dadas. E a fazemos inconscientemente. Este é o detalhe que falta a Maturana: a produção inconsciente. Mas, para chegar a isso, seria preciso que Maturana aplicasse o modelo freudiano do inconsciente, o que, aparentemente, ele ignora. A vantagem de Freud, diante dos pensadores de seu tempo, foi a de ter lido e utilizado Nietzsche, que introduzia na filosofia o componente conflito e luta por poder, tirando-a da tranqüilidade serena e calma das alturas da reflexão filosófica. Isso permitiu a Freud a acuidade crítica em relação à soci- 
edade, fato esse desprezado pelos pensadores de origem cientificista e positivista, como era freqüenta nas ciências naturais. Ao contrário, Maturana está mais próximo de Spencer que, no século 19, já comparava as estruturas e as funções sociais às estruturas e funções biológicas estudadas anteriormente. Trata-se da busca de um esquema otimista que pudesse submeter o social ao biológico, aparando todas as arestas de "anomias" sociais que lhe parecessem estranhas ou inconvenientes. Assim, o "corpo" social ou "máquina autopoiética" deveriam funcionar conforme as leis carentes de contradição da biologia e assim o fazem acredita Maturana.

Vimos que Maturana acha que não tem sentido falar de um mundo real, objetivo, independente do observador. Que não tem sequer sentido dizer que esteja aí e que eu não possa conhecê-lo. A discussão sobre a existência ou não do mundo real aparece com os construtivistas ditos "radicais", como é o caso de Niklas Luhmann. Nos parágrafos finais do Cap. 1 de A realidade dos meios de comunicação, ele: "O construtivismo operacional jamais duvida que haja um meio externo. Se duvidasse, não teria sentido nem mesmo o conceito de limites sistêmicos, que pressupõe que há outro lado. A tese do construtivismo operacional não conduz, assim, a nenhuma 'perda de mundo', ele não nega que a realidade exista. Não obstante, ela não pressupõe o mundo como objeto mas, em sentido fenomenólogico, como horizonte. Quer dizer, como algo inatingível". Katherine Hayles, em Cultural Critique (no prelo), numa citação do próprio Luhmann, no mesmo lugar, é comentada assim: "Hayles acredita que fora do sistema que opera cognitivamente haja um fluxo inacessível, atuando sem mediações, por assim dizer, um fluxo em si. Para ela, um sistema cognitivo, contudo, só consegue obter certeza de realidade mantendo contato com esse mundo externo, mesmo que só possa fazê-lo a partir do lado interno das fronteiras do sistema. 'Apesar de poder não haver um lado de fora que possamos conhecer, há numa fronteira'," p. 40. Mas, então, esse contato deveria ter uma estrutura híbrida, sem parte interna nem externa."

Que há a autopoiese, nos termos de Maturana, ou o fechamento operacional, nos termos de Luhmann, é inegável. A questão é a importância que se deve atribuir ao acoplamento estrutural, às interações, em suma, às interferências do meio na autogestão da própria percepção. Porque, como vimos acima, no exemplo citado "Você não vê os defeitos do outro porque gosta dele", existe uma clara identificação de um tipo de cegueira que varia conforme a pessoa, a circunstância, a época e outros fatores. Podemos estar mais ou menos cegos, tanto individual quanto coletivamente. Isso ainda não implica que a realidade externa tenha desaparecido por completo, como quer Maturana.

Efetivamente jamais a captaremos "objetivamente" com nossos órgãos dos sentidos. Os instrumentos nos auxiliam na redução desse subjetivismo, mas também sofrem ação deturpadora da técnica e do próprio homem. Toda essa discussão remete-nos de volta ao tema da verdade. Em outra obra, criticamos a posição do positivista Richard Rorty, que em sua empreitada contra o essencialismo abolia, da mesma forma que Maturana, as possibilidades de existência de um real. Tudo o que existe só existe na linguagem já era uma frase utilizada por ele naquele debate. Rorty, contudo, foi confrontado com o argumento da física de partículas, segundo o qual mesas e árvores possuem partículas elementares, organizadas de tal e tal modo que não dependem de modo algum da linguagem para existir e tenta uma saída que, de fato, foge da pergunta: este seria o último refúgio do encantamento, os físicos estariam buscando criar uma divindade para reivindicar uma participação em sua existência divina. Tampouco Maturana está livre da posição metafísica, ao assumir a preservação da identidade apesar de sucessivas mudanças de aparência, fato esse que não passa do conceito filosófico de substância, ousia, aquilo que permanece o mesmo.

Não há uma realidade, como sugerimos acima, mas realidades e observadores, sem correlação entre si. O raciocínio é homólogo ao da discussão sobre a verdade e a interpretação em Nietzsche. Aí fala-se que não há uma verdade assim como não há uma mulher, o que se tem é uma multidão de mulheres e esse é o modelo nietzscheano de interpretação, é uma proliferação de perspectivas interpretativas concorrentes. No trabalho de deciframento o que se tem a fazer é levá-lo, como disse Derrida, o mais longe possível, a um limite expandido talvez.

A contribuição da psicanálise, se aplicada ao método de Maturana, não se limitaria, naturalmente, à fonte junguiana, de que ele faz uso, com os conceitos de consciência coletiva, arquétipos. É preciso ir mais fundo e operar com a verdadeira revolução no pensamento, que foi Sigmund Freud, e complementar a exposição dos organismos autopoiéticos com a ressalva de que mutilamos a realidade que captamos do meio externo, em maior ou em menor grau, individual como coletivamente, segundo mecanismos inconscientes que nos fazem não ver as coisas, que funcionam como pontos cegos, mas não meramente ópticos, como os de von Foerster, mas pontos cegos inconscientes que são, estes sim, os verdadeiros responsáveis por nossas mutilações perceptivas, pela falsificação da percepção, com vistas ao atendimento de nossas necessidades internas autopoiéticas.

Caberia também reavaliar o campo de atuação dos acoplamentos estruturais e rever a afirmação de que nada no ambiente externo efetivamente provoca mudanças no interior de um organismo autopoético. $\mathrm{Na}$ descrição de Niklas Luhmann, utilizamo-nos da metáfora da janela, em que o sistema fechado vê o mundo lá fora como do lado de cá de uma janela, promovendo em si mesmo as alterações apenas observando esse mundo, sem que as alterações por si mesmas inva- 
dam a interioridade de cada um. Maturana sequer utiliza-se da expressão "sistemas observantes", mas tampouco dá elementos que informem melhor como se dá essa interação com o exterior que, em alguns casos, leva a transformações bem mais significativas do que supõe uma lógica de não-intervenção. Efetivamente, o meio externo altera. Se a janela de Luhmann é quebrada por uma pedra, uma bala ou é arrombada por ladrões, o mundo externo invade meu mundo sem que isso signifique necessariamente que meu sistema morra por causa disso. Mas ele deverá dar conta da nova realidade. E isso é o que têm dificuldade de assumir essas posturas. Se Luhmann dizia que, diante de uma situação conflituosa e complicada "deve-se observar" e Maturana diz que "deve-se avaliar as formas de convivência das partes, para ver onde falhou a entrega do amor", parece que falta algo de mais efetivo nessas visões que depositam excessiva importância no fato de serem sistemas fechados. Boa parte de nossa interioridade é, de fato, totalmente fechada ao mundo externo, a dor da gente efetivamente ninguém a conhece. Mas outra parte, não apenas uma membrana, não tão pequena nem tão insignificante de fato entra em jogo com o mundo externo realizando trocas, evoluções e transformações. A comunicação pode permitir isso.mFAmecos

\section{NOTAS}

Sobre o debate entre aristotélicos e pirrônicos, ver Montaigne, Ensaios II, cap. 12, p. 234. Sobre a inalcançabilidade da vista humana, sobre o vinho e o ferro, idem, p. 260. Sobre a inexistência de peso e calor, idem, p. 264. Sobre os cirenaicos: ver Montaigne, p. 271. Sobre Luhmann, ver final do Cap. 1, de Luhmann, 2005. A citação seguinte de Montaigne está na pág. 277.

Sobre Humberto Maturana. Consultar Beer, 1972e, p. xii a p. xvi. Linguagem como armadilha, cf. Beer, 1972, p. xvi.

Sobre teleologia, intenção e input/output. Beer, 1972, p. 67. Sobre o homem no submarino, ver Maturana e Varela, 1995, p. 166. O caso dos carneirinhos e das meninas da Índia está em, idem, pp. 158.

Elementos positivistas em Maturana. Do positivismo sociológico, conforme os conceitos de solidariedade orgânica de Émile Durkheim, ver Maturana, 1997, 184. A sociedade não se rege pelo conflito mas pela harmonização: Maturana, 2001, p. 97,185 . O sistema social se traduz como "sistema amoroso", onde há relações fraternas (Maturana, 2001, p. 108). A competição, para Maturana, não é uma relação social (Maturana, 2001, 109): “A história dos seres vivos não se realiza pela competição mas pela conservação de certos modos de vida" $(2001,109)$.
A questão do tamanho do cérebro entre os hominídeos. Consultar: Maturana, 2001, p. 91 e 96. O humano surge, na história evolutiva da linhagem hominídeo a que pertencemos, ao surgir a linguagem: 1997, p. 173. Ou: "é o modo de vida hominídeo que torna possível a linguagem..." Maturana, 1997, p. 174.

Linguagem é usada no sentido genérico de "comunicação". Maturana, 2001, p. 73. Linguagem é o "fluir do viver juntos, Maturana, 2001, p. 178. Uma linguagem que dispensa a significação. Maturana, 2001, p. 86. As palavras são nós, cf. Maturana, 2001, p. 88.

O círculo tautológico sem saída do nominalismo de Maturana: 1997, p. 346 Sobre a pergunta do público, ver Maturana, 2001, 99. Sobre a diferença com Wittgenstein: Maturana, 2001, p. 101.

Sobre a contradição de Maturana. As posições "conservadoras" diante da técnica estão em Maturana, 1997, p. 336.

Somos máquinas autopoiéticas. 1972, M/V, p. 78-79. Sobre organização, identidade e estrutura: $\mathrm{M} / \mathrm{V}$, 1995, p. 133. As máquinas autopoiéticas são autônomas, têm individualidade, são unidades, não têm input nem output, cf. Maturana e Varela, 1972, pp. 80-81. A estrutura são os componentes + as relações entre eles (cf. Maturana, 2001,p. 77).

O método de Maturana. Cf. Maturana, 1997, p. 81. Primeiro vem o processo, depois o fenômeno. Ver para isso: Maturana, 1997, p. 5, p. 81 e também Maturana, 2001, p. 56 e p. 59.

Objetividade sem parênteses e objetividade entre parênteses. A referência a entes independentes do observador está em Maturana, 2001, p. 34 . O acesso privilegiado à verdade em idem, p. 35. $O$ fato de haver muitas realidades, tantas quanto observadores está em Maturana, idem, p. 37. A convivência entre pesquisadores baseada na compreensão está em: Maturana, 2001, p. 39 e 40. A sedução na ciência está em Maturana, idem, $\mathrm{p}$. 121 a 123.

A realidade externa não existe. Maturana, 1972, pp. 50 e 52. O cérebro não capta informações, ele fabrica mundos, ver Maturana e Varela, 1995, p. 195.

Sistemas são fechados e abertos ao mesmo tempo. Ver Maturana, 2001, p. 175. O meio não pode interferir, V. Maturana, 1997, p. 67, 84-5. O caso do sistema nervoso está em Maturana, 1997, p. 99 e as "perturbações" estão em Maturana, 1997, p. 80.

Existem os objetos que eu vejo? Os objetos surgem da linguagem, ver Maturana, 1997, p. 73. Os seres 
humanos geram as coisas das quais eles falam, Maturana, 1997, p. 157. Antes da linguagem não há objetos, pode ser conferido em Maturana, 2001, p. 100. A citação "Se no momento em que estou na linguagem...", está em idem, ibidem. O caso dos dois observadores, ver Maturana, 1997, p. 101.

Sobre a percepção. A comparação (nossa) com Merleau-Ponty e a "resposta" de Maturana e Varela estão em, 1995, p. 66. Apesar de não existir o mundo, diz Maturana que "compartilhamos um mundo", em 1995, p. 251. Não diferença entre percepção e ilusão, ver Maturana, 1997, p. 73., Maturana, 2001, pp. 32-33. Sobre a formação de imagens e sons, ver Maturana e Varela, 1995, p. 191.

O caso da Salamandra. Consultar Maturana e Varela, 1995, p. 157. Lançar a língua não é apontar para um objeto, ver Maturana, 2001, p. 21, 24 e 64. Sobre o fato de animais não errarem, ver Maturana, 1997, p. 79. Sobre a salamandra esperada e a salamandra não esperada, ver Maturana, 1997, p. 100.

Sobre a linguagem: antes conotação do que denotação. Maturana, 1972, p. 30-31. Linguagem não é transmissão de informação. Idem, 1972, p. 32. E mais: Maturana, 1972, 50). A realidade não é necessária à linguagem. Maturana, 1997, p.73. Palavras são nós de coordenações. Maturana, 1997, pp. 116 e 168. Comunicação e interação: processos distintos. M/V, 1972, 120. Interação e comunicação. (M, 1972, 27-28).

Definição de comunicação: "condutas coordenadas, mutuamente desencadeadas entre os membros de uma comunidade. Uma classe particular de conduta". (M/V, 1995, p. 216). Comunicação = "coordenação comportamental num domínio de acomplamento estrutural" (M/V, 1995,218). Não se transmite informação: "Não há informação transmitida na comunicação. Cada um diz o que diz e ouve o que ouve segundo sua própria determinação estrutural". (M/V, 1995,219). "realização, em dois indivíduos, de suas respectivas autopoieses. Para o observador, interessa o 'significado' disso; para os interagentes interessa o acoplamento estrutural dos participantes". (M/V, 1995,230).

Comunicação, homomorfismo e aparecimento do novo. Maturana, 1997, p. 155-6.

Sociedade como reino de Deus. Maturana, 1997, p. 208.

Amor, nosso fator estabilizador básico. Beer, 1972, p. xxvi. Amor: "olhar o outro como igual" (M/V, 1995,263). O amor sobrevém às tragédias: Cada vez que há destruições, fracassos, guerras, quando se acaba essa loucura de destruição, o que aflora sempre é o amor. (conf. Maturana, 1997, p. 44). Não requer justificação: Maturana, 1997, p. 184.

A sociedade no fundo é solidariedade. Maturana, 1997, p. 46 e 177. Nosso principal problema: falta de amor. Maturana, 1997, p. 320. Maturana e os estudantes. Maturana, 2001, p. 117.

Nós criamos o mundo vivendo-o. Cf. citação de Maturana, 1997, p. 163.

\section{REFERÊNCIAS}

BEER, Stafford [1972]. “Introdução”. Em: Maturana [1972].

COHEN, Robeert S. [1972] e Marx W. Wartofsky. Apresentação. Em : Maturana [1972].

LUHMANN, Niklas [2005]. A realidade dos meios de comunicação. Trad. de Ciro marcondes Filho. São Paulo, Paulus, 2005.

MARCONDES FILHO, C. [2004]. O escavador de silêncios. Formas de construir e desconstruir sentidos na comunicação. São Paulo, Paulus, 2004.

MATURANA, Humberto [1972], e Francisco Varela. Autopoiesis and Cognition. The Realisation of the Living, Dordrecht, D. Reidel, 1980. [Título original : De maquinas y seres vivos, Santiago, Editorial Universitaria S.A., 1972].

[1995], e Francisco Varela: Árvore do conhecimento. As bases biológicas do entendimento humano. Trad. Jonas Pereira dos Santos, Campinas, Psy II, 1995.

[1997]. A ontologia da realidade. (Org. Cristina Magro, Miriam Graciano, Nelson Vaz) Belo Horizonte, Ed. UFMG.

[1997b] e Francisco Varela. De máquinas e seres vivos. Autopoiese: A organização do vivo. Tradução de Juan Acuña Llorens. Porto Alegre, Artes Médicas.

[ [2001]. Cognição, ciência e vida cotidiana. Org. e trad. de Cristina Magro e Victor Paredes. Belo Horizonte, Ed., UFMG, 2001.

MERLEAU-PONTY, M. [1945]. Phénoménologie de la perception. Paria, Gallimard.

MONTAIGNE, Michel de [1987]. Ensaios. Tradução de Sérgio Milliet. São Paulo, Nova Cultural. 